\title{
Glycolysis promotes caspase-3 activation in lipid rafts in T cells
}

\author{
Michael A. Secinaro ${ }^{1}$, Karen A. Fortner ${ }^{1}$, Oliver Dienz ${ }^{1,2}$, Angela Logan ${ }^{3}$, Michael P. Murphy ${ }^{3}$, Vikas Anathy ${ }^{4}$, \\ Jonathan E. Boyson ${ }^{1,2}$ and Ralph C. Budd ${ }^{1}$
}

\begin{abstract}
Resting T cells undergo a rapid metabolic shift to glycolysis upon activation in the presence of interleukin (IL)-2, in contrast to oxidative mitochondrial respiration with IL-15. Paralleling these different metabolic states are striking differences in susceptibility to restimulation-induced cell death (RICD); glycolytic effector $T$ cells are highly sensitive to RICD, whereas non-glycolytic T cells are resistant. It is unclear whether the metabolic state of a $T$ cell is linked to its susceptibility to RICD. Our findings reveal that IL-2-driven glycolysis promotes caspase-3 activity and increases sensitivity to RICD. Neither caspase-7, caspase-8, nor caspase-9 activity is affected by these metabolic differences. Inhibition of glycolysis with 2-deoxyglucose reduces caspase-3 activity as well as sensitivity to RICD. By contrast, IL-15driven oxidative phosphorylation actively inhibits caspase-3 activity through its glutathionylation. We further observe active caspase-3 in the lipid rafts of glycolytic but not non-glycolytic T cells, suggesting a proximity-induced model of self-activation. Finally, we observe that effector T cells during influenza infection manifest higher levels of active caspase-3 than naive T cells. Collectively, our findings demonstrate that glycolysis drives caspase-3 activity and susceptibility to cell death in effector T cells independently of upstream caspases. Linking metabolism, caspase-3 activity, and cell death provides an intrinsic mechanism for $T$ cells to limit the duration of effector function.
\end{abstract}

\section{Introduction}

The balance of cell proliferation and cell death is critical for the maintenance of stable cell numbers and tissue homeostasis. Thus, it is perhaps not surprising that these opposing processes may be mechanistically linked in various cell types, including cancer ${ }^{1,2}$. During an immune response, $\mathrm{T}$ lymphocytes undergo a period of very rapid proliferation. During this expansion, T cells also become susceptible to T-cell receptor (TCR) restimulationinduced cell death (RICD) $)^{3,4}$. However, the link between proliferation and susceptibility to death remains poorly understood $^{5}$.

Changes in cellular metabolism are well recognized to play a critical role during an effective immune response.

\footnotetext{
Correspondence: Ralph C Budd (ralph.budd@med.uvm.edu)

${ }^{1}$ Vermont Center for Immunology and Infectious Diseases, Larner College of Medicine, University of Vermont, Burlington, VT, USA

${ }^{2}$ Department of Surgery, Larner College of Medicine, University of Vermont, Burlington, VT, USA

Full list of author information is available at the end of the article Edited by $\mathrm{G}$. Raschellà
}

Resting naive $\mathrm{T}$ lymphocytes, upon activation, undergo a dramatic metabolic shift from oxidative phosphorylation to aerobic glycolysis ${ }^{6-8}$. The switch to a largely glycolytic state allows the cell to generate the synthetic capacity needed for rapid proliferation and effector function, such as cytokine production. In a similar manner, B cells and dendritic cells also utilize glycolysis upon activation to enable their effector functions ${ }^{9,10}$. Recent studies have further indicated that the metabolic state of effector $\mathrm{T}$ cells helps determine their subset differentiation ${ }^{11}$. Differing metabolic states are also known to be involved in the specification of T-cell memory, with central memory $\mathrm{T}$ cells exhibiting high oxidative phosphorylation and effector memory $\mathrm{T}$ cells being more glycolytic ${ }^{12-14}$.

It is well appreciated that cell death and metabolism are closely linked. Glycolytic enzymes can be induced by the same transcription factors that upregulate the expression of anti-apoptotic proteins such as BCL- $\mathrm{xL}^{15}$. Other proteins with metabolic function, such as cytochrome c, are directly involved in cell death ${ }^{15,16}$. When released from 
the mitochondria, cytochrome c activates caspase-9, which then cleaves caspase-3 and induces apoptosis. Caspase- 3 can be alternatively activated through cleavage by caspase- 8 , which is activated by death receptors such as Fas (CD95). However, little is known regarding possible links between metabolism and caspase activity.

Although caspases were originally defined for their role in cell death, it is now appreciated that caspases perform many functions in cells in addition to cell death ${ }^{17,18}$. This is particularly well established for caspase-8, an initiator caspase that can induce apoptosis upon ligation of a death receptor $^{19}$, but can also allow cell proliferation by inhibiting formation of the necroptosome and induction of necroptosis $^{20}$. Active caspase-3, a critical downstream mediator of apoptosis, has also been observed in nondying cells and is implicated in skeletal muscle differentiation $^{21}$, T-cell anergy ${ }^{22}$, B-cell cycling ${ }^{10}$, and erythrocyte maturation ${ }^{17}$. However, these studies did not examine how caspase- 3 activity is being regulated in these non-apoptotic situations. Moreover, an explanation has been lacking for the molecular switch between TCRstimulated proliferation of naive $\mathrm{T}$ cells vs. induction of cell death in effector $\mathrm{T}$ cells ${ }^{3,4}$.

Given the involvement of caspases in both cell death and non-death functions, regulation of caspase activity and its location in cells are of paramount importance in determining cell fate. We have observed that $\mathrm{T}$ cells grown in interleukin (IL) -2 vs. IL-15 have similar amounts of total pro-caspase-3, but IL-2-cultured $\mathrm{T}$ cells have a substantially higher level of active caspase-3, and as a result are much more susceptible to RICD $^{23}$. IL-15-cultured T cells are resistant to this form of cell death, in part due to the high levels of reactive oxygen and nitrogen species that lead to the redox modification of a critical cysteine in the active site of caspase-3, resulting in its inactivation ${ }^{23-25}$. IL-2 and IL15 also induce very different metabolic states in T cells; IL-2 promotes glycolysis, whereas IL-15 upregulates oxidative phosphorylation ${ }^{12}$. We now observe that caspase-3 activity in non-dying effector $\mathrm{T}$ cells is largely a function of their glycolytic state. Inhibition of glycolysis by a variety of methods reduces caspase- 3 activity and protects $\mathrm{T}$ cells from RICD. In addition, IL-15cultured $\mathrm{T}$ cells further reduce caspase- 3 activity through its inactivation by glutathionylation. These findings underscore the importance of cellular metabolism in the regulation of caspase- 3 activity and susceptibility toward cell death.

\section{Results}

IL-15 induces mitochondrial ROS and glutathionylation of caspase-3

To investigate the influence of cell metabolism on caspase activity, we initially modeled two metabolic states in vitro using cytokines that are known to promote very different levels of glycolysis following T-cell activation: IL2 , which upregulates glycolysis, and IL-15, known to induce a non-glycolytic state of mitochondrial respiration $^{12}$. To mimic an immune response in vitro, purified naive $\mathrm{T}$ cells were activated with anti-CD3/CD28 in the presence of IL-2 for 2 days, and then removed from stimulation and propagated in IL-2 for an additional day. The activated $\mathrm{T}$ cells were then washed thoroughly to remove exogenous cytokines and recultured in medium containing either IL-2 or IL-15 for an additional 3 days. In agreement with previous observations ${ }^{12}$, IL-15-cultured $\mathrm{T}$ cells manifested high mitochondrial respiration, as reflected by a high oxygen consumption rate (OCR; Fig. 1a). Consistent with these findings, complex I activity of the electron transport chain was higher in IL-15cultured $\mathrm{T}$ cells than in IL-2-cultured T cells (Figs. 1b, c). Complex $\mathrm{I}$ is known to generate reactive oxygen species $(\mathrm{ROS})^{26}$, and we determined that IL-15 induced a greater amount of mitochondrial ROS compared to IL-2 (Fig. 1d) as measured using the mitochondria-targeted probe mitoboronic acid (MitoB) ${ }^{27}$. MitoB is converted to mitophenol (MitoP) upon reaction with mitochondrial hydrogen peroxide, and the levels of MitoB and MitoP are then measured by liquid chromatography tandem mass spectrometry and expressed as a ratio of MitoP to MitoB ${ }^{27}$.

ROS can promote protein glutathionylation, a process that results in the reversible modification of a cysteine by glutathione ${ }^{28}$. Caspase- 3 has been shown previously to be inactivated in HL-60 cells by the glutathionylation of the critical cysteine in the enzymatic pocket ${ }^{25}$. We therefore investigated the possibility that caspase- 3 is glutathionylated in IL-15-cultured T cells. Glutathionylated proteins were immunoprecipitated and immunoblotted for caspase-3 (Fig. 2a). Caspase-3 was glutathionylated to a considerably greater extent in the IL-15-cultured T cells compared to IL-2 (Fig. 2b). Of interest, the glutathionylation was observed specifically on cleaved caspase-3 (Fig. 2a). This implies that fulllength pro-caspase- 3 was initially cleaved and then inactivated by glutathionylation.

Given that IL-15 induced a greater amount of mitochondrial ROS compared to IL-2 (Fig. 1d), we examined the effect of quenching mitochondrial ROS on overall caspase activity in activated T cells. IL-2- and IL-15cultured $\mathrm{T}$ cells were incubated with the mitochondriatargeted antioxidant mitoquinone (MitoQ) to quench mitochondrial $\operatorname{ROS}^{29}$. MitoQ treatment of IL-15-cultured $\mathrm{T}$ cells, but not IL-2-cultured $\mathrm{T}$ cells, induced a reduction in ROS (Fig. 2c). The lack of effect of MitoQ in IL-2cultured $\mathrm{T}$ cells may reflect a non-mitochondrial source of ROS, such as cytoplasmic NADPH oxidases. Consistent with these findings, MitoQ did not alter caspase activity in 

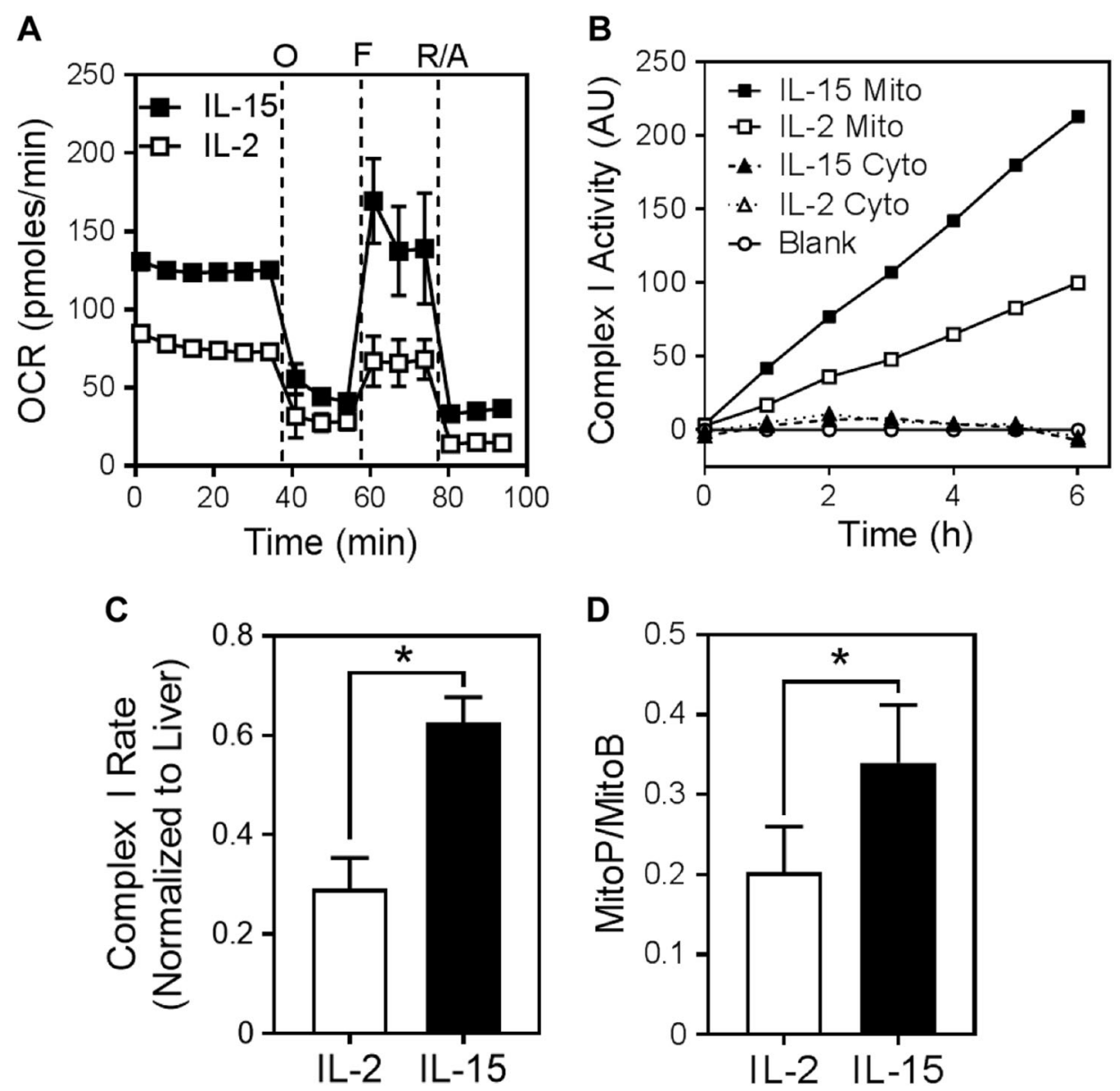

Fig. 1 IL-15 drives increased oxygen consumption, complex I activity, and mitochondrial ROS. Anti-CD3/CD28-activated T cells were cultured for 3 days in IL-2 or IL-15. a Oxygen consumption rate (OCR) was measured by extracellular flux analysis. O Oligomycin A (inhibitor of ATP synthase), F FCCP (uncoupler of the electron transport chain), R/A Rotenone and Antimycin (inhibitors of complexes I and III, respectively; mean \pm S.D. of four replicates within the one experiment shown. The graph is representative of two independent experiments). $\mathbf{b}$ Complex I activity was measured in mitochondrial (Mito) and cytosolic (Cyto) fractions of IL-2- or IL-15-cultured T cells (the graph is representative of two independent experiments). c Complex I rates of activity in (b) for mitochondrial fractions, normalized to the rate of activity of complex I in mouse liver mitochondria (unpaired $t-$ test; ${ }^{*} p<0.05$; mean \pm S.D. of data from two independent experiments). $\mathbf{d}$ Mitochondrial ROS were measured by the conversion of mitoboronic acid (MitoB) to mitophenol (MitoP), and the ratio of MitoP/MitoB was measured by liquid chromatography tandem mass spectrometry (paired $t$-test; ${ }^{*} p<$ 0.05; mean \pm S.E.M. of means from three independent experiments)

IL-2-cultured $\mathrm{T}$ cells, but did slightly increase caspase activity in IL-15-cultured T cells, although not to the level of caspase activity in IL-2-cultured T cells (Fig. 2d). Consistent with these findings, treatment with MitoQ did not affect the sensitivity of IL-2- or IL-15-cultured T cells to death, either before or after restimulation (Fig. 2e). Thus, mitochondrially derived ROS partially contributed to the low level of caspase activity in IL-15-cultured $\mathrm{T}$ cells, but were not solely responsible for the decreased sensitivity to RICD. We therefore considered that the pronounced metabolic shift to glycolysis during T-cell activation might also influence the activity of certain caspases and sensitivity to RICD.

\section{Glycolysis drives caspase-3 activation}

Glycolysis was measured by extracellular acidification rate (ECAR) in naive T cells, effector T cells (day 6 after activation), and late effector $\mathrm{T}$ cells (day 10 after activation). Glycolysis increased initially from naive to day 6 $\mathrm{T}$ cells, and then decreased from day 6 to day 10 (Fig. 3a). These changes were greater in the IL-2-cultured $\mathrm{T}$ cells than IL-15. IL-2 signaling is known to drive glycolysis ${ }^{12}$, and the kinetics of glycolysis in $\mathrm{T}$ cells grown in IL-2 closely paralleled the levels of surface IL-2 receptor $\alpha$ (CD25) expression, which also peaked and declined over a nearly identical timespan (Fig. 3b). These results are consistent with previously reported kinetics of CD25 


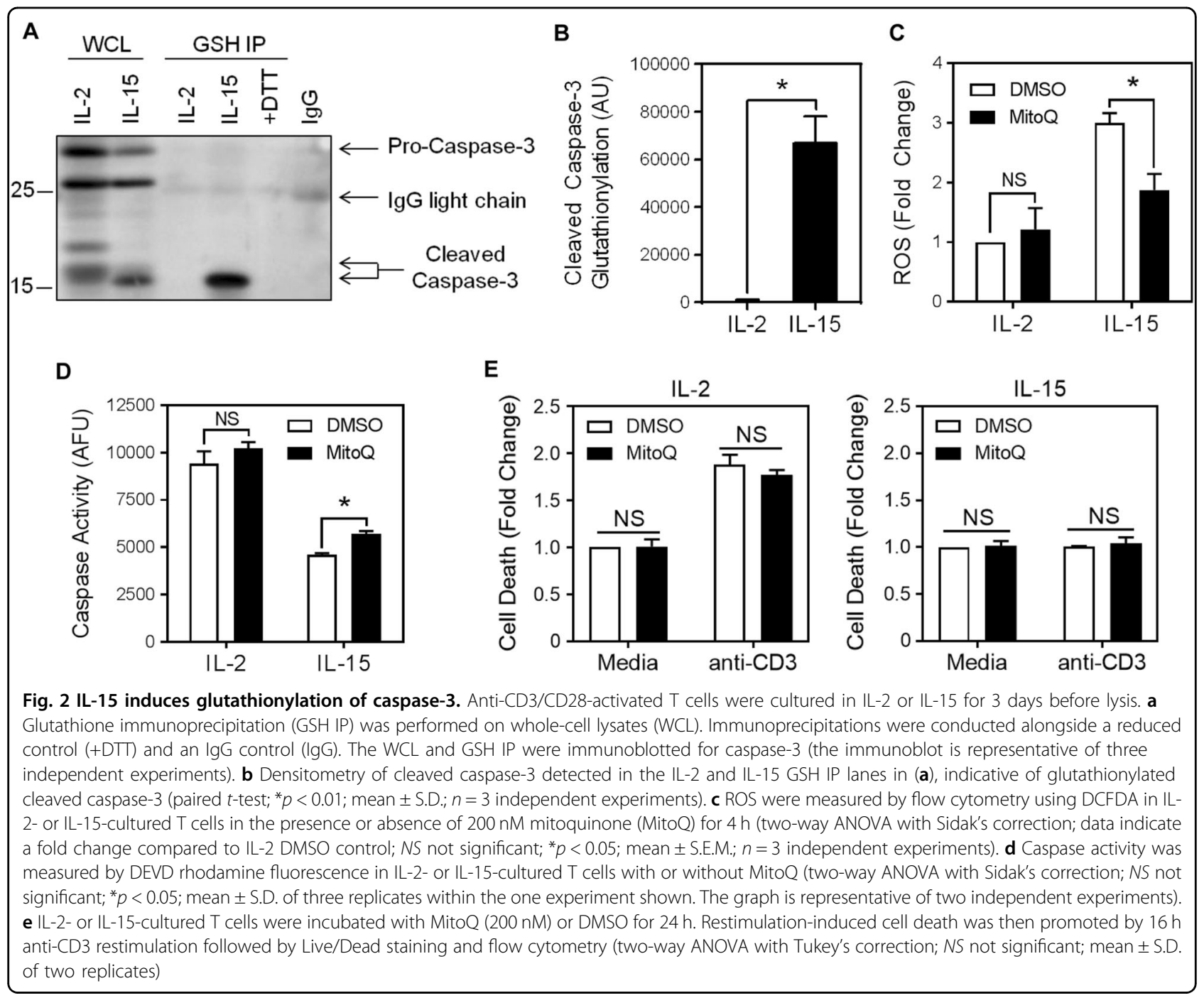

expression $^{30}$. Concomitant with the rise of glycolysis and surface CD25 expression following T-cell activation, we observed an increase in total caspase activity. $\mathrm{T}$ cells propagated in IL-2 continued to increase caspase activity until a peak on day 6, after which it declined through day 10 , closely paralleling ECAR and CD25 expression (Fig. 3c). As a result of the culturing system and the introduction of IL-15 on day 3, the first measurements of caspase activity and CD25 expression occurred on day 4 for IL-15-cultured T cells. In the presence of IL-15, CD25 expression and caspase activity remained at a consistently low level throughout the same 10-day period (Fig. 3c). The largest difference in caspase activity between IL-2and IL-15-cultured T cells was on day 6 . We also measured the level of active caspase- 3 by flow cytometry, and found it to be greater in IL-2-cultured T cells compared with IL-15-cultured T cells on day 6 (Fig. 3d). Whereas caspase- 3 activity was detected in live IL-2-cultured $\mathrm{T}$ cells, activity was much higher in cells in which death was induced through Fas stimulation (Fig. 3d). Thus, the intermediate levels of active caspase- 3 in proliferating $\mathrm{T}$ cells were not due to contaminating dead cells, but rather were present in all IL-2-cultured T cells.

To extend the observed correlation of glycolysis with caspase activity, we examined $\mathrm{CD} 4^{+}$T-cell functional subsets, which have been shown to have varying levels of glycolytic activity ${ }^{11}$. In vitro-differentiated T helper (Th) 1 and Th2 cells were reported to have high levels of glycolysis, being slightly higher in Th2 cells. By contrast, in vitro-differentiated $\mathrm{T}$ regulatory (Treg) cells had low levels of glycolysis. Purified naive $\mathrm{CD}^{+} \mathrm{T}$ cells were differentiated into Th1, Th2, and Treg cells in vitro and their caspase activity was measured. Caspase activity was highest in the Th2 subset and lowest in the Treg subset, matching glycolytic activity (Figs. 3e and f).

These collective findings suggested that glycolysis and caspase activity might be causally linked. We thus examined more directly the effect of glycolysis on caspase 


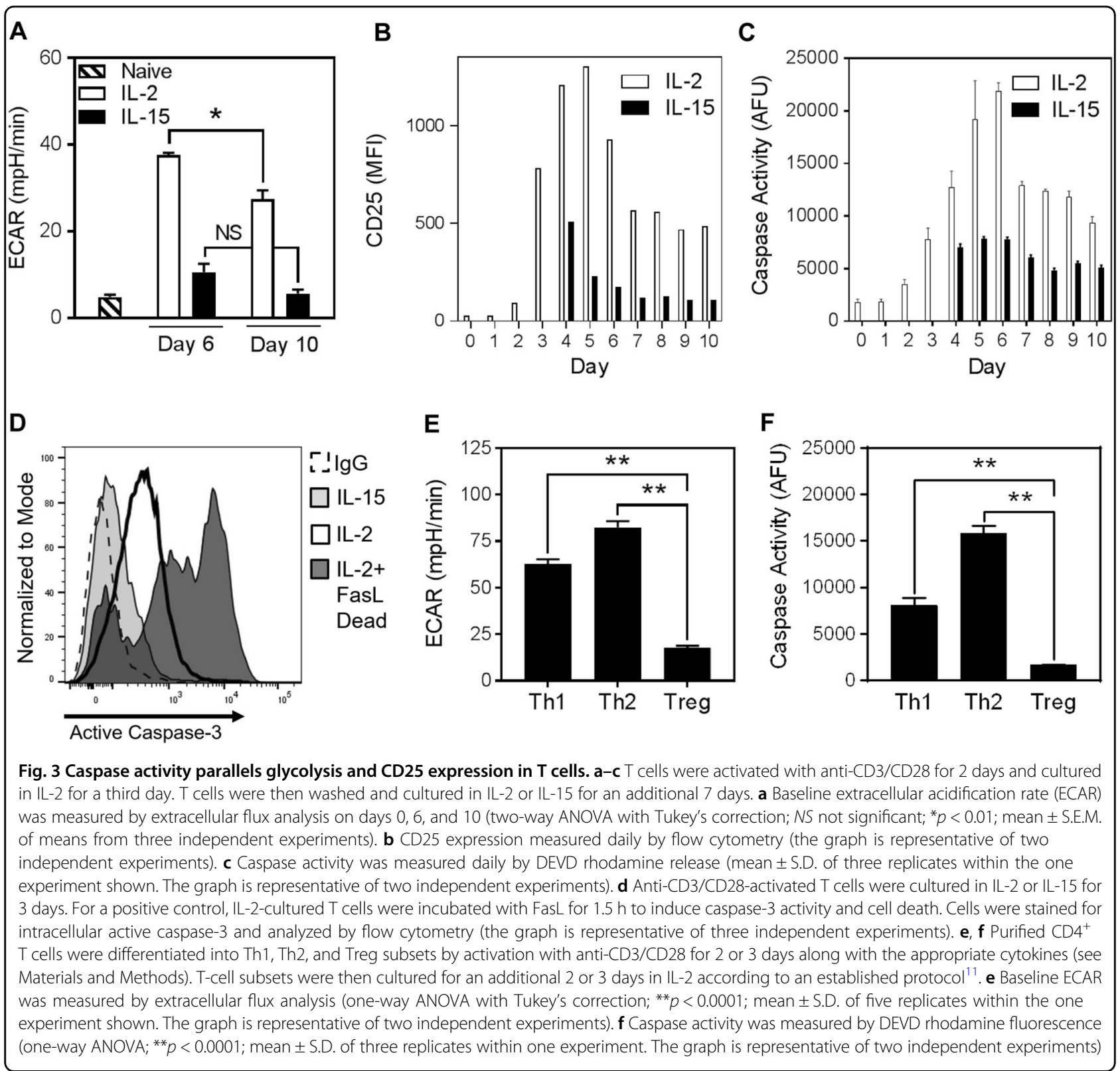

activity. To inhibit glycolysis, IL-2-cultured T cells were incubated with 2-deoxy-D-glucose (2-DG), a glucose analog that blocks glucose catabolism after phosphorylation by hexokinase ${ }^{31}$. As an inhibitor of glycolysis, 2-DG could potentially induce cell death in highly glycolytic IL2 -cultured $\mathrm{T}$ cells. To reduce contamination by dead cells, the 2-DG cell cultures were centrifuged over Histopaque. The inhibition of glycolysis by 2-DG was confirmed by measuring a decrease in ECAR (Fig. 4a). In parallel, caspase activity was also decreased, in a dose-dependent manner, in IL-2-cultured $\mathrm{T}$ cells cultured with 2-DG (Fig. 4b). To confirm that the decrease in caspase activity was due to the inhibition of glycolysis and not an offtarget effect of 2-DG, we also inhibited glycolysis by two other methods, culturing IL-2-cultured $\mathrm{T}$ cells with rapamycin or in a low-glucose medium. These treatments also reduced caspase activity in IL-2-cultured $\mathrm{T}$ cells (Fig. 4b) but not in IL-15-cultured T cells (Fig. 4c).

To determine whether the regulation of caspase activity by glycolysis was selective for certain caspases, we examined the levels of specific caspase activity in IL-2cultured $\mathrm{T}$ cells in the presence or absence of 2-DG, using biotin-VAD (bVAD) to selectively precipitate only active caspases with streptavidin-coated Sepharose beads. Immunoblot analysis of the precipitates revealed that 2-DG caused a profound decrease in caspase- 3 activity, but had no effect on the activities of the related effector caspase-7, nor the upstream caspase- 8 or caspase- 9 (Figs. 5a, b). 

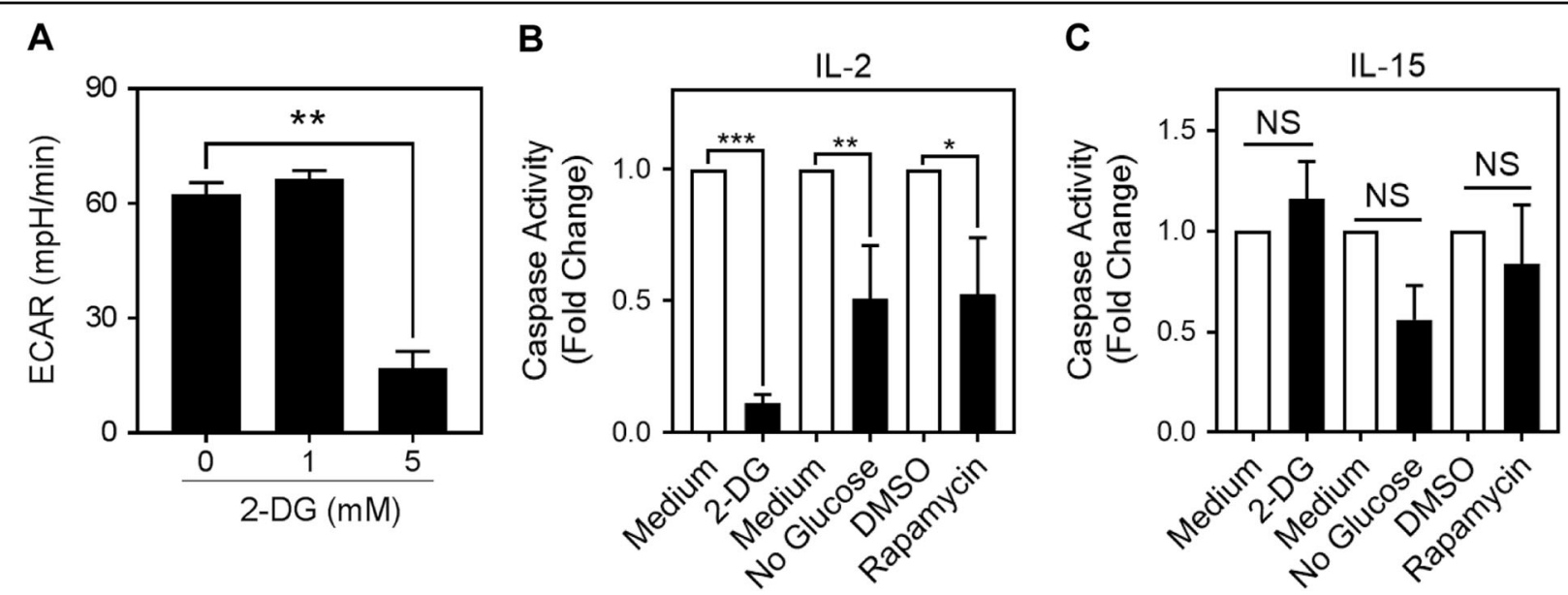

Fig. 4 Glycolysis regulates caspase activity in effector T cells. Anti-CD3/CD28-activated T cells were cultured for 3 days in IL-2 with (a) 2deoxyglucose (2-DG, 0-5 mM). Baseline ECAR was measured (one-way ANOVA with Dunnett's correction; ** $p<0.001$; mean \pm S.E.M. of means from three independent experiments). b, c Activated T cells were cultivated for 3 days in (b) IL-2 or (c) IL-15, in medium, 2-deoxyglucose (2-DG, 5 mM), without glucose (No glucose), Rapamycin (300 nM), or DMSO control. Caspase activity was measured by DEVD rhodamine fluorescence. Data indicate a fold change compared to the control (one-way ANOVA with Dunnett's correction; ${ }^{*} p<0.05$; ${ }^{* *} p<0.001 ;$ mean \pm S.D.; $n=3$ independent experiments)

The disparate levels of active caspase-3 in glycolytic vs. non-glycolytic $\mathrm{T}$ cells suggested that they might differ in their susceptibility to cell death following TCR restimulation. Day 6 IL-2-cultured T cells cultured with and without 2-DG were restimulated with anti-CD3. While 2DG induced more cell death prior to restimulation (Fig. 5c), the 2-DG-treated cells were considerably more resistant to RICD (Fig. 5d). RICD is primarily mediated by Fas-ligand (FasL) signaling ${ }^{32}$. Therefore, we measured FasL by western blot and found expression to be highest in glycolytic IL-2-cultured T cells, and slightly less in nonglycolytic IL-15-cultured and 2-DG-treated $\mathrm{T}$ cells (Figs. 5e, f). However, the fact that the activities of caspases- 8 and -9 were not affected by 2-DG suggests that FasL did not mediate caspase-3 activity in viable IL-2cultured $\mathrm{T}$ cells.

\section{Active caspase- 3 is sequestered in membrane lipid rafts in effector $T$ cells}

Self-cleavage of caspases can occur when pro-caspases are clustered in close proximity ${ }^{33}$, such as in lipid rafts where caspase- 8 is known to be active in effector $\mathrm{T}$ cells ${ }^{34,35}$. To determine whether caspase- 3 was localized to membrane lipid rafts in effector $\mathrm{T}$ cells, lipid rafts were purified from both glycolytic, IL-2-cultured T cells, and non-glycolytic, IL-15-cultured T cells, and the resulting fractions were analyzed for caspase- 3 cleavage and activity. In IL-2-cultured glycolytic T cells, pro-caspase- 3 was present primarily in the non-raft fractions, and to a much lesser extent in the raft fractions (Fig. 6a, raft fractions: 3-5; non-raft fractions: 10 and 11). However, caspase-3 was extensively cleaved only in the lipid raft fractions. In the IL-15-cultured non-glycolytic T cells, pro-caspase-3 was also found predominantly in the non-raft fractions. Although caspase- 3 was also observed to be cleaved primarily in the raft fractions of IL-15-cultured T cells, it was to a lesser extent than in IL-2-cultured T cells (Fig. 6b). Hence, the ratio of cleaved caspase- 3 to pro-caspase- 3 was greater in the lipid rafts of IL-2-cultured glycolytic T cells than in non-glycolytic IL-15-cultured T cells (Fig. 6c).

To confirm that the cleaved caspase- 3 observed in lipid rafts was active, we performed a bVAD precipitation on the lipid raft fractions 3-5 and the non-raft fraction 11 . Caspase- 3 was found to be active at a much greater extent in the raft fractions of IL-2-cultured glycolytic T cells, compared with IL-15-cultured non-glycolytic $\mathrm{T}$ cells (Figs. 6d, e).

\section{Caspase-3 activity increases in effector T cells during influenza infection}

To determine whether active caspase- 3 is observed in activated $\mathrm{T}$ cells in vivo, mice were infected intranasally with influenza virus strain A/Puerto Rico/8/1934 H1N1 (Flu) and lymphocytes from the lung-draining mediastinal lymph node were analyzed after 6 days. Caspase-3 activity was measured in naive $\left(\mathrm{CD} 44^{\text {low }}\right)$ and proliferating effector $\left(\mathrm{CD} 44^{\text {high }}\right) \mathrm{CD} 4^{+}$and $\mathrm{CD} 8^{+} \mathrm{T}$ cells (Fig. 7a). The percentage of active caspase-3-positive cells, as well as the median fluorescence intensity (MFI) of active caspase- 3 staining, were increased in the $\mathrm{CD} 44^{\text {high }}$ population of both $\mathrm{CD}^{+}$and $\mathrm{CD}^{+}{ }^{+} \mathrm{T}$ cells after Flu infection, compared to the CD44 ${ }^{\text {low }}$ population (Fig. $7 \mathrm{~b}$ ). 


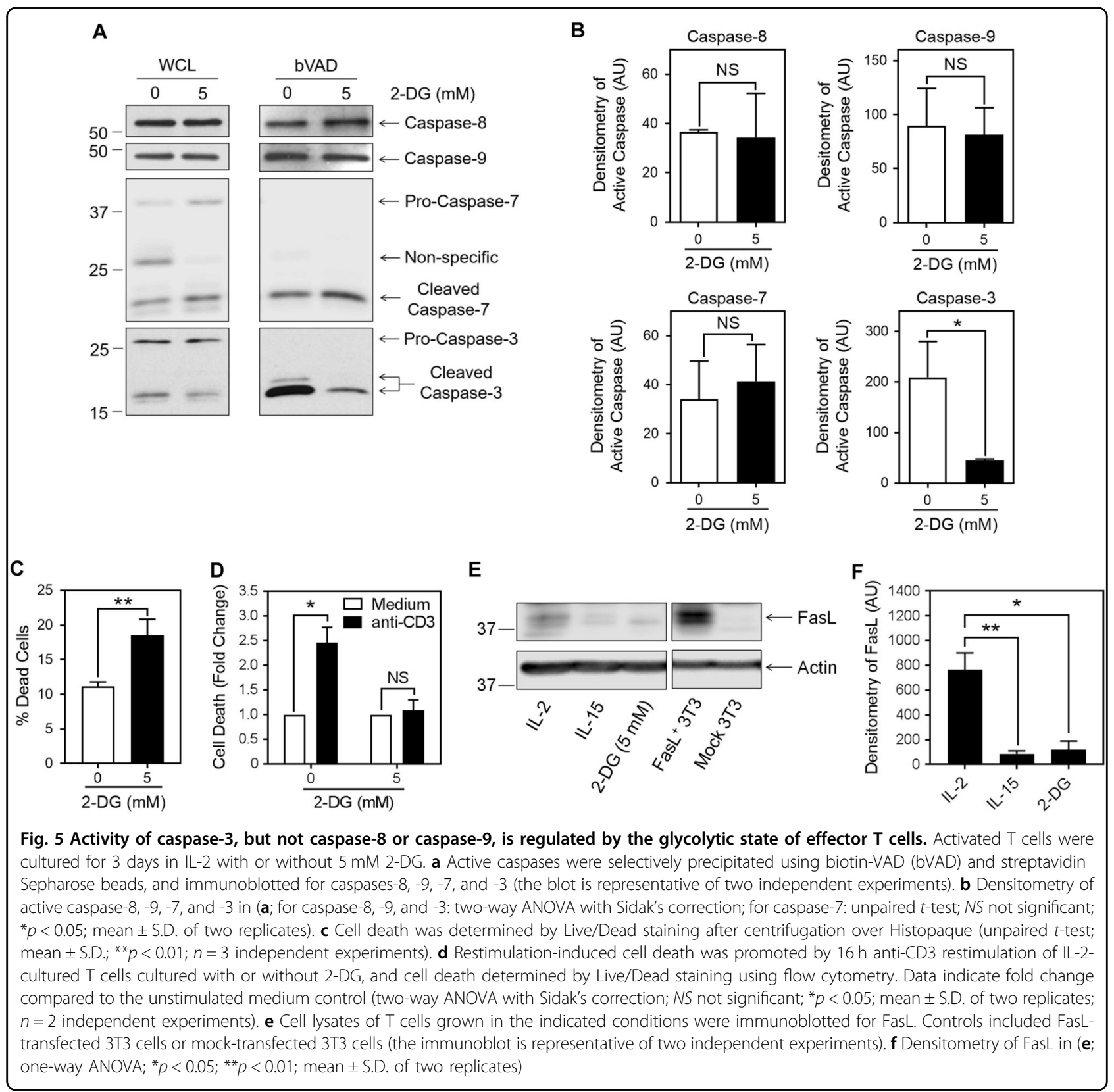

\section{Discussion}

The present findings reveal that IL-2-mediated glycolysis increases caspase- 3 activity and the consequential susceptibility of effector $T$ cells to caspase-3-mediated cell death. IL-15, by contrast, drives low levels of glycolysis that favor low caspase-3 activity. The high amount of oxidative metabolism in IL-15-cultured T cells also promotes a further decrease in caspase- 3 activity through its glutathionylation. Our data support a model by which glycolytic metabolism sets the stage for a high proliferative rate of effector $\mathrm{T}$ cells that is coupled to enhanced susceptibility to death cues through the activity of downstream effector caspase-3.
Cleavage of caspase-3 can be induced by upstream caspase- 8 following Fas ligation, and by caspase- 9 following cytochrome c release from the mitochondria. It is also possible for cleavage of caspase- 3 to occur by selfactivation when caspase- 3 molecules are clustered in close proximity $^{33,36}$. We observed that the levels of both caspase- 8 and caspase- 9 activity were similar between glycolytic and non-glycolytic $\mathrm{T}$ cells, suggesting that they are not likely to be the regulators of caspase- 3 activity in these different metabolic states. The findings are also consistent with our previous observations that caspase-3 activity persists in effector $\mathrm{T}$ cells in which caspase- 8 was deleted $^{37}$. It is possible that translocation to the cell 


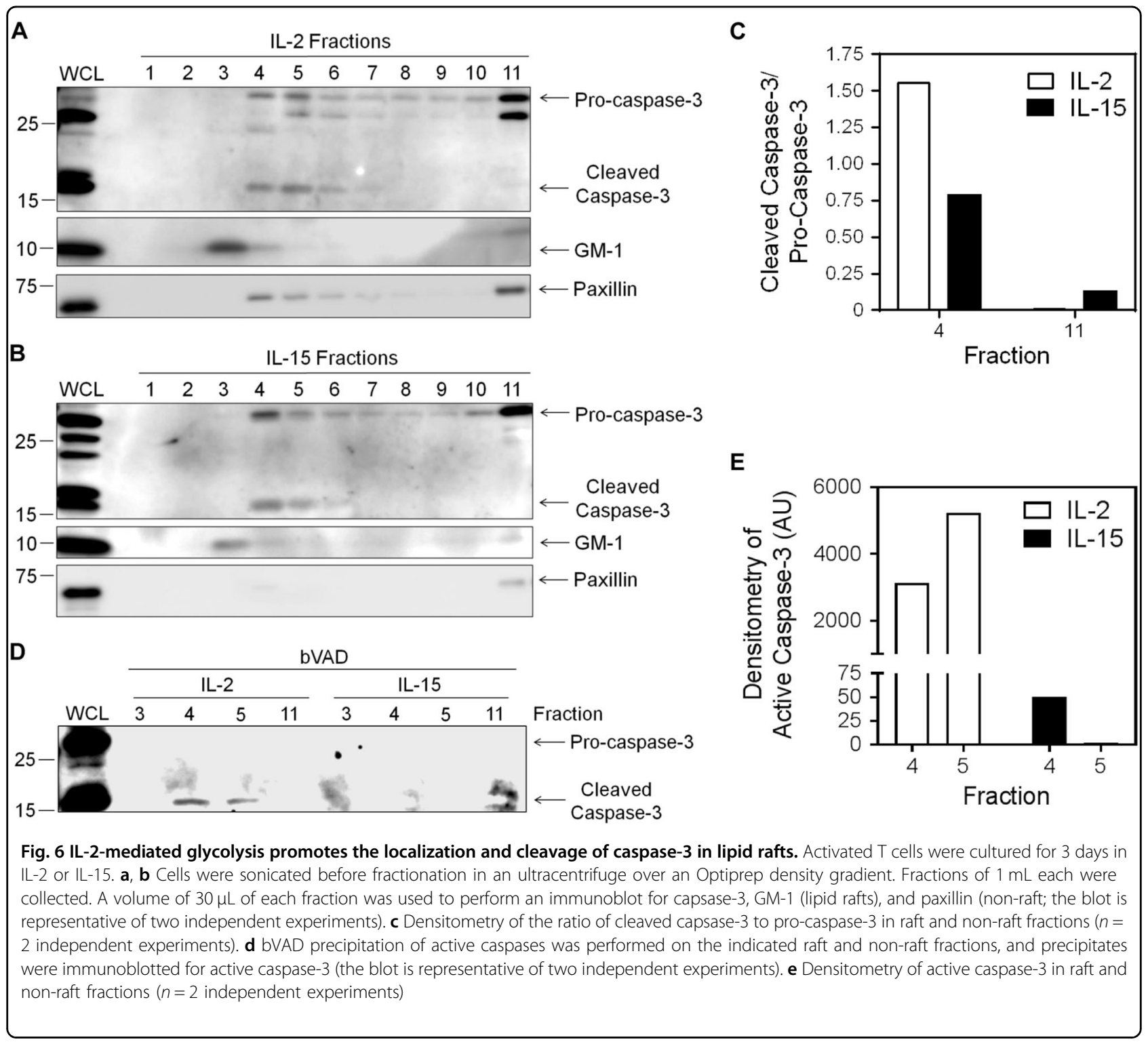

membrane, and particularly to lipid raft domains, allows the clustering of full-length inactive caspase- 3 , and could promote its proximity-induced autocleavage and activation $^{36,38}$. Furthermore, while confined to lipid rafts, active caspase- 3 may also be restricted in its access to substrates that might induce cell death.

Effector $\mathrm{T}$ cells and memory $\mathrm{T}$ cells have very different metabolic profiles. Similar to memory $\mathrm{T}$ cells derived in vivo, memory-like $\mathrm{T}$ cells can be generated in vitro through IL-15 signaling that promotes oxidative phosphorylation $^{12,13}$. Consistent with those previous reports, we observed that compared to IL-2, IL-15-cultured T cells have elevated oxidative phosphorylation and mitochondrial ROS. Our findings further reveal that IL-15-cultured $\mathrm{T}$ cells manifest glutathionylation of caspase-3, which is known to inactivate caspase- 3 at the critical cysteine in the enzymatic pocket ${ }^{25}$. Given that glutathionylation of caspase-3 was detected only of cleaved caspase-3 in IL-15cultured $\mathrm{T}$ cells, this suggests that caspase- 3 is being inactivated by glutathionylation after its cleavage. Along with our previous report of the inactivation of caspase-3 by $\mathrm{S}$-nitrosylation ${ }^{23}$, these data show that in $\mathrm{T}$ cells caspase-3 can be inactivated by redox-dependent posttranslational modifications, which are influenced by the metabolic state of the cell. Metabolically induced modifications of apoptotic caspases may be an important mechanism for memory $\mathrm{T}$-cell formation.

The correlation between glycolysis and CD25 expression for in vitro-generated effector $\mathrm{T}$ cells is not surprising, given the known role of $\mathrm{IL}-2$ in the induction of 


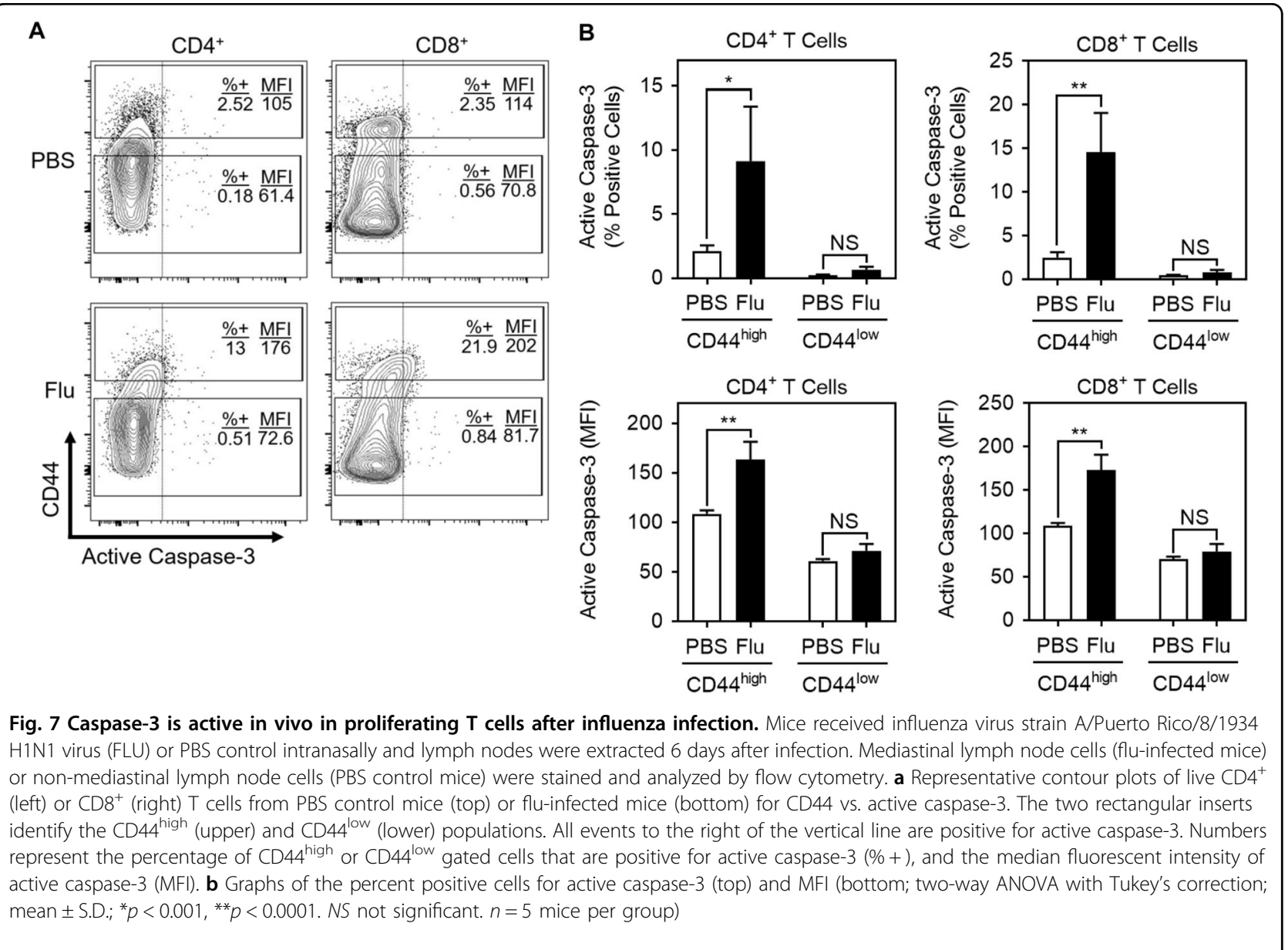

glycolysis in T cells. However, in vitro-differentiated Treg cells, despite expressing high levels of CD25, are not glycolytic, likely due to their derivation with $\mathrm{TGF}^{11,39}$. We observed that these cells have low caspase activity, indicating that caspase activity is a function of glycolysis rather than $\mathrm{CD} 25$ expression.

Proliferating $\mathrm{T}$ cells are known to be susceptible to cell death cues such as RICD $^{40,41}$. Our data demonstrate independent increases in both FasL and caspase-3 activity in glycolytic IL-2-cultured T cells prior to TCR restimulation. Consistent with our observations, a study recently reported that human $\mathrm{CD}^{+} \mathrm{T}$ cells rapidly induced FasL protein following TCR restimulation only when glycolytic, rendering them more susceptible to $\mathrm{RICD}^{42}$. However, we do not feel that the caspase- 3 activity or the caspase- 8 activity in proliferating glycolytic $\mathrm{T}$ cells is due to Fas/ FasL interactions for a few reasons. First, we observed no increased levels of active upstream caspase-8 in IL-2cultured $\mathrm{T}$ cells despite more active caspase- 3 . Second, we have previously shown that Fas-deficient effector $\mathrm{T}$ cells express as much active caspase- 8 as wild-type $\mathrm{T}$ cells ${ }^{35}$. Finally, reducing caspase- 8 activity in effector $\mathrm{T}$ cells by deleting its regulator, c-FLIP, had no effect on the levels of active caspase- $3^{37}$. Hence, the collective findings would indicate that the levels of active caspase- 8 and caspase- 3 in effector $T$ cells are largely independent of one another as well as independent of Fas/FasL interactions.

At present, the full spectrum of function of caspase-3 activity in viable effector $\mathrm{T}$ cells is unclear. Other reports have noted a role for caspase- 3 in T-cell anergy ${ }^{22}$, cleavage of p21 and cell cycling in $\mathrm{B}$ cells ${ }^{10}$, skeletal muscle differentiation ${ }^{21}$, and maturation of erythrocytes, macrophages, and dendritic cells ${ }^{17}$. The localization of active caspase- 3 in membranes could provide access to substrates important to these functions, while simultaneously preventing the enzyme from cleaving pro-death substrates. While it is possible that the glycolytic state of cells may influence these other reported functions of caspase-3, the current findings nonetheless link metabolism to caspase- 3 activity and thus provide a plausible regulatory mechanism of immune cell homeostasis.

\section{Materials and methods \\ Mice}

C57BL/6NJ male mice (Jackson Laboratory, Bar Harbor, $\mathrm{ME})$ were housed in an Association for Assessment and 
Accreditation of Laboratory Animal Care Internationalapproved facility at the University of Vermont Larner College of Medicine. Mice were used at 2-6 months of age, and protocols were approved by the Institutional Animal Care and Use Committee.

\section{Cell culture}

$\mathrm{T}$ cells were purified from mouse lymph nodes (axillary, inguinal, brachial, and cervical) and spleens by negative selection as described previously ${ }^{23}$. Briefly, lymph nodes and spleens were homogenized through nylon mesh and red blood cells were lysed with Gey's solution. Combined lymphocytes and splenocytes were incubated on ice for 30 min with the following antibodies: anti-CD11b (M1/ 70), anti-MHC class II (M5/114/15/2; a kind gift from M. Rincón, Larner College of Medicine, University of Vermont, Burlington, VT, USA), and anti-B220 (RA36B2). Cells were then rocked over magnetic goat anti-rat beads (Qiagen, Germantown, MD, USA) at a 10:1 bead:cell ratio for $45 \mathrm{~min}$ at $4{ }^{\circ} \mathrm{C}$. Beads and bound cells were removed with a magnet. Naive $\mathrm{T}$ cells were cultured in RPMI-1640 (Corning, Manassas, VA, USA), supplemented with $25 \mathrm{mM}$ HEPES, $100 \mathrm{U} / \mathrm{mL}$ penicillin-streptomycin (ThermoFisher Scientific, Waltham, MA, USA), 5\% bovine calf serum (GE Healthcare HyClone, Logan, UT, USA), 2.5 $\mathrm{mg} / \mathrm{L}$ glucose, $2 \mathrm{mM}$ glutamine, $10 \mu \mathrm{g} / \mathrm{mL}$ folate, $1 \mathrm{mM}$ pyruvate, and $50 \mu \mathrm{M}$ 2-mercaptoethanol (RPMI-C) and stimulated on $10 \mu \mathrm{g} / \mathrm{mL}$ plate-bound anti-CD3 clone 1452C11 (Bio X Cell, West Lebanon, NH, USA) and soluble anti-CD28 ascites clone 37-51 (1:1000), supplemented with $50 \mathrm{U} / \mathrm{mL}$ IL-2 (Cetus, Emeryville, CA, USA) at $37^{\circ} \mathrm{C}$, $5 \% \mathrm{CO}_{2}$. After 2 days, activated $\mathrm{T}$ cells were removed from stimulation and cultured for an additional day in RPMI-C and $50 \mathrm{U} / \mathrm{mL}$ IL-2. Cells were then washed three times to remove cytokines and cultured for 2-3 more days in RPMI-C supplemented with either $50 \mathrm{U} / \mathrm{mL}$ IL-2 or $20 \mathrm{ng} /$ mL IL-15 (a kind gift from Amgen, Thousand Oaks, CA, USA). For studies of the inhibition of glycolysis, $\mathrm{T}$ cells were activated for 2 days in RPMI-C medium supplemented with $50 \mathrm{U} / \mathrm{mL} \mathrm{IL}-2$. Cells were then washed three times and cultured in RPMI-C medium with $50 \mathrm{U} / \mathrm{mL}$ IL-2 and the indicated doses of 2-deoxy-D-glucose (SigmaAldrich, St. Louis, MO, USA) or rapamycin (MP Biomedicals, Solon, OH, USA) for 3 days, replacing media, cytokine, and inhibitor each day. IL-2-cultured $\mathrm{T}$ cells cultured in 2-deoxy-D-glucose were centrifuged over Histopaque-1077 (Sigma-Aldrich) to minimize the number of dead cells in the cultures prior to use in the assays. Alternatively, cells were washed and cultured with glucosefree RPMI-1640 (Corning) supplemented with $100 \mathrm{U} / \mathrm{mL}$ penicillin-streptomycin, $5 \%$ bovine calf serum, $2 \mathrm{mM}$ glutamine, $10 \mu \mathrm{g} / \mathrm{mL}$ folate, $1 \mathrm{mM}$ pyruvate, and $50 \mu \mathrm{M} 2-$ mercaptoethanol (GF RPMI-C). Cells were then cultured in GF RPMI-C supplemented with the indicated decreasing concentrations of glucose for 3 days, replacing the media each day.

\section{Caspase activity assay}

Caspase activity was measured using the Apo-ONE Homogeneous Caspase-3/7 Assay Kit (Promega, Madison, WI, USA) according to the manufacturer's specifications. Samples were analyzed using a Synergy HT Plate Reader (BioTek, Winooski, VT, USA).

\section{Cell lysis and immunoblot analysis}

Cells were lysed for $20 \mathrm{~min}$ on ice in Lysis Buffer A (0.5\% Nonidet P-40, $150 \mathrm{mM} \mathrm{NaCl}, 20 \mathrm{mM}$ Tris- $\mathrm{HCl}(\mathrm{pH}$ 7.4), $10 \%$ glycerol, $2 \mathrm{mM}$ sodium orthovanadate, and Complete Protease Inhibitor (Roche Diagnostics, Indianapolis, IN, USA)). Protein concentration was determined by Bradford Assay (Bio-Rad, Hercules, CA, USA). Lysates were boiled for $5 \mathrm{~min}$ in Laemmli loading buffer supplemented with 2-mercaptoethanol (2-ME). Proteins within the lysates were separated by SDS-PAGE on a $12 \%$ acrylamide gel and transferred to a polyvinylidene difluoride (PVDF) membrane (Bio-Rad). Membranes were blocked in $4 \%$ milk in Tris-buffered saline with $0.1 \%$ Tween-20 (American Bioanalytic, Natick, MA, USA) at room temperature for $1 \mathrm{~h}$. The following antibodies were used for protein detection: anti-caspase-3, 585 rabbit polyclonal antibody (a kind gift from Dr. Yuri Lazebnik, Cold Spring Harbor Laboratories, Cold Spring Harbor, NY, USA), anti-caspase-8 (a kind gift from Dr. Andreas Strasser, The Walter and Eliza Hall Institute of Medical Research, Melbourne, Australia), anti-caspase-9, clone 5B4 (Stressgen Assay Designs, Ann Arbor, MI, USA), antiflotillin (BD Biosciences), GM-1 HRP (Sigma-Aldrich), anti-paxillin, clone 165 (BD Biosciences), anti-FasL MAB5262 (R\&D Systems, Minneapolis, MN, USA), anti$\beta$-actin (Sigma-Aldrich), anti-mouse IgG HRP, anti-rabbit IgG HRP, and anti-rat IgG HRP (all from Jackson Laboratory). Densitometry was performed using Image Studio Lite v5 (LI-COR Biotechnology, Lincoln, NE, USA).

\section{bVAD active caspase precipitation}

Cells were washed once with PBS containing 1\% bovine serum albumin (PBS/1\% BSA) and once with PBS, and then incubated on ice for at least $20 \mathrm{~min}$ with Lysis Buffer B (0.2\% Nonidet P-40,150 mM NaCl, $20 \mathrm{mM}$ Tris- $\mathrm{HCl}$ (pH 7.4), $10 \%$ glycerol, $2 \mathrm{mM}$ sodium orthovanadate, and Complete Protease Inhibitor (Roche Diagnostics)) supplemented with $20 \mu \mathrm{M}$ biotin-VAD-fmk (bVAD; MP Biomedicals). Protein was quantified by Bradford assay (Bio-Rad). Overall, 400-600 $\mu$ g of protein in $300 \mu \mathrm{L}$ of Lysis Buffer B (or $250 \mu \mathrm{g}$ of protein for lipid raft fractions with no extra buffer added) was pre-cleared by rocking over $40 \mu \mathrm{L}$ of Sepharose $4 \mathrm{~B}$ beads (Sigma-Aldrich) for $2 \mathrm{~h}$ at $4{ }^{\circ} \mathrm{C}$. Supernatants were then rocked over streptavidin-Sepharose 
beads (ThermoFisher Scientific) overnight at $4{ }^{\circ} \mathrm{C}$. Beads were then washed three times with Lysis Buffer B without protease inhibitor and boiled for $5 \mathrm{~min}$ in Laemmli loading buffer supplemented with 2-ME. For precipitations with lipid raft and non-raft fractions, an equal amount of protein was used from each fraction for the assay.

\section{Glutathione immunoprecipitation}

Cells were washed once with PBS/1\% BSA and once with PBS, and then incubated in Lysis Buffer B supplemented with $1 \mathrm{mM} \mathrm{N}$-ethylmaleimide for at least $20 \mathrm{~min}$ on ice. Protein was quantified by Bradford assay (BioRad). An amount of $300 \mu \mathrm{g}$ of lysate was brought to 250 $\mu \mathrm{L}$ with lysis buffer. The reduced control was incubated with $50 \mathrm{mM}$ dithiothreitol (+DTT) and rocked at $4{ }^{\circ} \mathrm{C}$ for $1 \mathrm{~h}$. The reduced sample was then centrifuged through a Micro Bio-Spin P-6 Gel Column (Bio-Rad). For the IgG control, $5 \mu \mathrm{g}$ of mouse IgG (Jackson Laboratory) was added to the sample. For all other samples, $2 \mu \mathrm{g}$ of antiglutathione antibody (Virogen, Watertown, MA, USA) was added. All samples were rocked overnight at $4{ }^{\circ} \mathrm{C}$. Samples were added to $50 \mu \mathrm{L}$ of washed Protein G Plus Agarose (ThermoFisher Scientific) and rocked at $4{ }^{\circ} \mathrm{C}$ for $1 \mathrm{~h}$. Beads were washed and boiled in Laemmli buffer before being loaded onto a $15 \%$ acrylamide gel. Proteins were separated by SDS-PAGE and transferred to a PVDF membrane for immunoblot analysis.

\section{Metabolic analyses}

OCRs and ECARs were measured using the Seahorse XFe 96 Analyzer (Agilent Technologies, Santa Clara, CA, USA) according to the manufacturer's specifications. Analysis was performed using the Wave Software v2.2.0 or v2.3.0.2 (Agilent Technologies).

\section{Flow cytometry}

For surface staining, cells were washed in PBS and stained with Live/Dead Fixable Blue Dead Cell Stain (ThermoFisher Scientific) for $25 \mathrm{~min}$ on ice. Cells were washed and incubated for $25 \mathrm{~min}$ on ice with anti-CD25BV421 (BioLegend, San Diego, CA, USA), anti-CD44-PE (BioLegend), anti CD4-PE-TexasRed (ThermoFisher Scientific), anti-CD8-PerCP-Cy5.5 (BioLegend), anti-TCR $\beta$ PE-Cy7 (BioLegend), and anti-CD45RB-FITC (BioLegend). Cells were washed, fixed in $1 \%(\mathrm{v} / \mathrm{v})$ methanol-free formaldehyde, and analyzed on an LSRII (BD Biosciences).

For intracellular staining, after staining with Live/Dead Fixable Blue Dead Cell Stain and surface antibodies as described above, cells were washed and fixed with $2 \%$ formaldehyde $(\mathrm{v} / \mathrm{v})$ for $15 \mathrm{~min}$ on ice. Fixed cells were washed and permeabilized with $\mathrm{PBS} / 1 \%$ BSA supplemented with $0.03 \%$ saponin for $10 \mathrm{~min}$ on ice. Cells were washed and incubated with anti-cleaved caspase-3 Alexa 647 (Cell Signaling) for $30 \mathrm{~min}$ on ice. Cells were washed, fixed in $1 \%$ formaldehyde $(\mathrm{v} / \mathrm{v})$, and analyzed on an LSRII (BD Biosciences).

All flow cytometry data were analyzed with FlowJo v10 software (FlowJo, Ashland, OR, USA).

\section{Cellular and mitochondrial ROS measurement}

Cellular ROS was measured using $2^{\prime}, 7^{\prime}$-dichlorodihydrofluorescein diacetate (DCFDA; ThermoFisher Scientific). Overall, $5 \times 10^{5}$ cells were incubated with $1 \mu \mathrm{M}$ DCFDA in PBS at $37^{\circ} \mathrm{C}$ in the dark for $30 \mathrm{~min}$. Cells were washed with cold PBS/1\% BSA and analyzed immediately by flow cytometry.

Mitochondrial ROS was quenched using MitoQ ${ }^{29}$. Cell cultures were incubated with MitoQ or a DMSO control for $4 \mathrm{~h}$. Cells were then stained with DCFDA, as described above, for ROS detection.

Mitochondrial ROS was measured using the MitoB probe as previously described ${ }^{27}$. MitoB specifically targets the mitochondria and is converted to MitoP in the presence of ROS. The ratio of MitoP/MitoB was measured using liquid chromatography tandem mass spectrometry.

\section{Complex I activity and mitochondrial extraction}

Cells were washed with PBS/1\% BSA and resuspended in STE buffer $(250 \mathrm{mM}$ sucrose, $5 \mathrm{mM}$ Tris, $1 \mathrm{mM}$ EGTA, pH 7.4 with $\mathrm{HCl}$ ). Cells were homogenized and centrifuged at $1000 \mathrm{~g}$ for $3 \mathrm{~min}$ at $4{ }^{\circ} \mathrm{C}$. The supernatant was then centrifuged at $10,000 \mathrm{~g}$ for $10 \mathrm{~min}$ at $4{ }^{\circ} \mathrm{C}$. The supernatant (cytosol) was saved and the pellet (mitochondria) was washed with STE buffer. The mitochondria were then resuspended and assayed for Complex I activity using the Complex I Enzyme Activity Microplate Kit (MitoSciences, Eugene, OR, USA) according to the manufacturer's specifications. Samples were run in parallel with mouse liver mitochondrial extracts as a positive control. Complex I rates were calculated by dividing Complex I activity by time. Complex I rates were normalized to mouse liver mitochondrial complex I rate.

\section{Cell death}

RICD was induced in day 6 or 7 effector T cells by incubation on plate-bound anti-CD3 $(10 \mu \mathrm{g} / \mathrm{mL})$ for $16-18 \mathrm{~h}$ at $37^{\circ} \mathrm{C}$. Cells were removed and stained with Live/Dead Fixable Blue Dead Cell Stain (ThermoFisher Scientific), fixed in $1 \%$ formaldehyde $(\mathrm{v} / \mathrm{v})$, and analyzed by flow cytometry.

As a positive control for cell death, day 6 effector T cells were incubated with $400 \mathrm{ng} / \mathrm{mL}$ FLAG-tagged FasL (Enzo Life Sciences, Farmingdale, NY, USA) and $2 \mu \mathrm{g} / \mathrm{mL}$ antiFLAG antibody M-2 (Sigma-Aldrich) for $1.5 \mathrm{~h}$ at $37^{\circ} \mathrm{C}$. Cells were then stained with Live/Dead Fixable Blue Dead Cell Stain (ThermoFisher Scientific) fixed in $1 \%$ formaldehyde (v/v) and analyzed by flow cytometry. 


\section{$\mathrm{CD4}^{+} \mathrm{T}$-cell subset differentiation}

Purified $\mathrm{CD}^{+} \mathrm{T}$ cells were activated in complete medium on plate-bound anti-CD3/soluble anti-CD28 for 2 or 3 days in the presence of differentiating cytokines (Th1: $4 \mathrm{ng} / \mathrm{mL}$ IL-12 (PeproTech, Rocky Hill, NJ, USA) plus $10 \mu \mathrm{g} / \mathrm{mL}$ anti-IL-4 (BioLegend); Th2: $10 \mathrm{ng} / \mathrm{mL}$ IL-4 (PeproTech) plus $10 \mu \mathrm{g} / \mathrm{mL}$ anti-IFN- $\gamma$ (BioLegend); Treg: 2 ng/mL TGF- $\beta$ (PeproTech) plus $100 \mathrm{U} / \mathrm{mL}$ IL-2). After differentiation, cultures were propagated for 2 or 3 days in complete medium containing $50 \mathrm{U} / \mathrm{mL}$ IL-2 for Th1 and Th2 cells, and $100 \mathrm{U} / \mathrm{mL}$ IL-2 for Treg.

\section{Lipid raft purification}

Lipid rafts were separated as previously described ${ }^{35}$. Briefly, cells were lysed on ice for $25 \mathrm{~min}$ in TNE buffer ( 5 $\mathrm{mM}$ iodoacetic acid (ThermoFisher Scientific), $150 \mathrm{mM}$ $\mathrm{NaCl}, 10 \mathrm{mM}$ Tris-HCl pH 7.4, 15 mM EDTA, Complete Protease Inhibitor) supplemented with $100 \mathrm{mM} \mathrm{Na} \mathrm{CO}_{3}$ and $0.5 \%$ Triton X-100. Lysates were sonicated and added to $60 \%$ Opti-Prep sucrose substitute (Sigma-Aldrich) to make a final concentration of $40 \%$ Opti-Prep. Lysates were placed in an ultracentrifuge tube and layered over with 30 and 5\% solutions of Opti-Prep diluted with TNE buffer. Samples were centrifuged for $18 \mathrm{~h}$ at $200,000 \mathrm{~g}$ at $4{ }^{\circ} \mathrm{C}$. Eleven $1 \mathrm{~mL}$ fractions were taken sequentially from each sample. An equal volume of each fraction was used for immunoblot analysis.

\section{Influenza infection of mice}

Mouse-adapted influenza virus strain A/Puerto Rico/ 8/1934 H1N1 (PR8) virus (Charles River Laboratories, Wilmington, MA, USA) was used to infect mice. Mice were briefly anesthetized using $2.3 \%$ isoflurane in oxygen and infected intranasally with a sublethal dose of PR8 (0.2 LD50) in $0.05 \mathrm{ml}$ of PBS. Control mice received $0.05 \mathrm{ml}$ PBS without virus. Mice were monitored daily until harvest on day 6 , at which time the mediastinal lymph node was harvested from the influenza-infected mice, and axillary, brachial, and inguinal lymph nodes were extracted from the PBS control mice. Lymphocytes were collected and stained for analysis by flow cytometry.

\section{Statistical analysis}

Statistical analyses were performed using the graphing software Prism v7 (GraphPad Software, La Jolla, CA, USA). The statistical test used for each experiment is indicated in the figure legends. The following statistical tests were used: paired and unpaired $t$-test when comparing two conditions (e.g., IL-2 compared to IL-15), oneway ANOVA with Tukey test, or Dunnett test (when comparing to one control) for correction for multiple comparisons when comparing multiple conditions for a single variable (e.g., dose titration of 2-DG), two-way
ANOVA with Sidak test, or Tukey test for correction for multiple comparisons when comparing multiple variables across multiple conditions (e.g., IL-2 with and without anti-CD3 compared to IL-15 with and without anti-CD3). All data met the assumptions of the statistical tests used and variation between the compared groups was similar.

\section{Acknowledgments}

We thank Dr. Roxana del Rio-Guerra for technical assistance with flow cytometry, as well as the Harry Hood Bassett Flow Cytometry and Cell Sorting Facility at the University of Vermont Larner College of Medicine for use of the BD LSRII. These studies were supported by National Institutes of Health grants R01HL122383 to V.A., Al055402, GM118228, and Al119979 to R.C.B., and Al1 19974 to J.E.B. The work in MPM's lab is supported by the Medical Research Council UK (MC_U105663142) and by a Wellcome Trust Investigator award $(110159 / Z / 15 / Z)$

\section{Author details}

${ }^{1}$ Vermont Center for Immunology and Infectious Diseases, Larner College of Medicine, University of Vermont, Burlington, VT, USA. Department of Surgery, Larner College of Medicine, University of Vermont, Burlington, VT, USA. ${ }^{3} \mathrm{MRC}$ Mitochondrial Biology Unit, University of Cambridge, Cambridge, UK. ${ }^{4}$ Department of Pathology and Laboratory Medicine, Larner College of Medicine, University of Vermont, Burlington, VT, USA

\section{Competing interests}

The authors declare that they have no competing financial interests.

\section{Publishers note}

Springer Nature remains neutral with regard to jurisdictional claims in published maps and institutional affiliations.

Received: 13 July 2017 Revised: 20 October 2017 Accepted: 24 October 2017

Published online: 19 January 2018

\section{References}

1. Evan, G. et al. Integrated control of cell proliferation and cell death by the c-myc oncogene. Philos. Trans. R Soc. Lond. B. Biol. Sci. 345, 269-275 (1994).

2. Wang, C., Tai, Y., Lisanti, M. P. \& Liao, D. J. c-Myc induction of programmed cell death may contribute to carcinogenesis: a perspective inspired by several concepts of chemical carcinogenesis. Cancer Biol. Ther. 11, 615-626 (2011).

3. Green, D. R., Droin, N. \& Pinkoski, M. Activation-induced cell death in T cells. Immunol. Rev. 193, 70-81 (2003).

4. Snow, A. L., Pandiyan, P., Zheng, L., Krummey, S. M. \& Lenardo, M. J. The power and the promise of restimulation-induced cell death in human immune diseases. Immunol. Rev. 236, 68-82 (2010).

5. Hedrick, S. M., Ch'en, I. L. \& Alves, B. N. Intertwined pathways of programmed cell death in immunity. Immunol. Rev. 236, 41-53 (2010).

6. Roos, D. \& Loos, J. A. Changes in the carbohydrate metabolism of mitogenically stimulated human peripheral lymphocytes. II. Relative importance of glycolysis and oxidative phosphorylation on phytohaemagglutinin stimulation. Exp. Cell Res. 77, 127-135 (1973).

7. Roos, D. \& Loos, J. A. Effect of phytohaemagglutinin on the carbohydrate metabolism of human blood lymphocytes after inhibition of the oxidative phosphorylation. Exp. Cell Res. 77, 121-126 (1973).

8. Hume, D. A., Radik, J. L., Ferber, E. \& Weidemann, M. J. Aerobic glycolysis and lymphocyte transformation. Biochem. J. 174, $703-709$ (1978).

9. Santambrogio, L. et al. Involvement of caspase-cleaved and intact adaptor protein 1 complex in endosomal remodeling in maturing dendritic cells. Nat. Immunol. 6, 1020-1028 (2005).

10. Woo, $\mathrm{M}$. et al. Caspase-3 regulates cell cycle in B cells: a consequence of substrate specificity. Nat. Immunol. 4, 1016-1022 (2003). 
11. Michalek, R. D. et al. Cutting edge: distinct glycolytic and lipid oxidative metabolic programs are essential for effector and regulatory CD4 $+\mathrm{T}$ cell subsets. J. Immunol. 186, 3299-3303 (2011).

12. van der Windt, G. J. et al. Mitochondrial respiratory capacity is a critical regulator of CD8 + T cell memory development. Immunity 36, 68-78 (2012).

13. O'Sullivan, D. et al. Memory CD8(+) T cells use cell-intrinsic lipolysis to support the metabolic programming necessary for development. Immunity 41, 75-88 (2014).

14. Phan, A. T. et al. Constitutive glycolytic metabolism supports CD8+T cell effector memory differentiation during viral infection. Immunity 45, 1024-1037 (2016).

15. Green, D. R., Galluzzi, L. \& Kroemer, G. Metabolic control of cell death. Science 345, 1250256 (2014)

16. Mason, E. F. \& Rathmell, J. C. Cell metabolism: an essential link between cell growth and apoptosis. Biochim. Biophys. Acta 1813, 645-654 (2011).

17. Lamkanfi, M., Festjens, N., Declercq, W., Vanden Berghe, T. \& Vandenabeele, P. Caspases in cell survival, proliferation and differentiation. Cell Death Differ. 14, 44-55 (2007)

18. Shalini, S., Dorstyn, L., Dawar, S. \& Kumar, S. Old, new and emerging functions of caspases. Cell Death Differ. 22, 526-539 (2015).

19. Medema, J. P. et al. FLICE is activated by association with the CD95 deathinducing signaling complex (DISC). EMBO J. 16, 2794-2804 (1997).

20. Dillon, C. P. et al. Survival function of the FADD-CASPASE-8-CFLIP(L) complex. Cell Rep. 1, 401-407 (2012).

21. Fernando, P., Kelly, J. F., Balazsi, K., Slack, R. S. \& Megeney, L. A. Caspase 3 activity is required for skeletal muscle differentiation. Proc. Natl Acad. Sci. USA 99 11025-11030 (2002)

22. Puga, I., Rao, A. \& Macian, F. Targeted cleavage of signaling proteins by caspase 3 inhibits T cell receptor signaling in anergic T cells. Immunity $\mathbf{2 9}$ 193-204 (2008).

23. Saligrama, P. T. et al. IL-15 maintains T-cell survival via S-nitrosylation-mediated inhibition of caspase-3. Cell Death Differ. 21, 904-914 (2014).

24. Mitchell, D. \& Marletta, M. Thioredoxin catalyzes the S-nitrosation of the caspase-3 active site cysteine. Nat. Chem. Biol. 1, 154-158 (2005).

25. Huang, Z., Pinto, J., Deng, H. \& Richie, J. Inhibition of caspase-3 activity and activation by protein glutathionylation. Biochem. Pharmacol. 75, 2234-2244 (2008).

26. Grivennikova, V. G. \& Vinogradov, A. D. Generation of superoxide by the mitochondrial Complex I. Biochim. Biophys. Acta 1757, 553-561 (2006).

27. Cochemé, $\mathrm{H}$. M. et al. Measurement of $\mathrm{H} 2 \mathrm{O} 2$ within living Drosophila during aging using a ratiometric mass spectrometry probe targeted to the mitochondrial matrix. Cell Metab. 13, 340-350 (2011).
28. Giustarini, D., Rossi, R., Milzani, A., Colombo, R. \& Dalle-Donne, I. S-glutathionylation: from redox regulation of protein functions to human diseases. J. Cell Mol. Med. 8, 201-212 (2004).

29. Kelso, G. et al. Selective targeting of a redox-active ubiquinone to mitochondria within cells: antioxidant and antiapoptotic properties. J. Biol. Chem. 276, 4588-4596 (2001).

30. Cantrell, D. A. \& Smith, K. A. Transient expression of interleukin 2 receptors Consequences for T cell growth. J. Exp. Med. 158, 1895-1911 (1983).

31. Wick, A. N., Drury, D. R., Nakada, H. I. \& Wolfe, J. B. Localization of the primary metabolic block produced by 2-deoxyglucose. J. Biol. Chem. 224, 963-969 (1957).

32. Alderson, M. R. et al. Fas ligand mediates activation-induced cell death in human T lymphocytes. J. Exp. Med. 181, 71-77 (1995).

33. Muzio, M., Stockwell, B. R., Stennicke, H. R., Salvesen, G. S. \& Dixit, V. M. An induced proximity model for caspase-8 activation. J. Biol. Chem. 273, 2926-2930 (1998)

34. Koenig, A., Russell, J. Q., Rodgers, W. A. \& Budd, R. C. Spatial differences in active caspase-8 defines its role in T-cell activation vs. cell death. Cell Death Differ. 15 1701-1711 (2008)

35. Misra, R. S. et al. Caspase-8 and c-FLIPL associate in lipid rafts with NFkappaB adaptors during T cell activation. J. Biol. Chem. 282, 19365-19374 (2007).

36. Shi, Y. Caspase activation: revisiting the induced proximity model. Cell 117, 855-858 (2004).

37. Koenig, A. et al. The c-FLIPL cleavage product p43FLIP promotes activation of extracellular signal-regulated kinase (ERK), nuclear factor B (NF-B), and caspase8 and T cell survival. J. Biol. Chem. 289, 1183-1191 (2014).

38. MacCorkle, R. A., Freeman, K. W. \& Spencer, D. M. Synthetic activation of caspases: artificial death switches. Proc. Natl Acad. Sci. USA 95, 3655-3660 (1998).

39. Delisle, J. S. et al. The TGF-[beta]-Smad3 pathway inhibits CD28dependent cell growth and proliferation of CD4 T cells. Genes Immun. 14, 115-126 (2013).

40. Kabelitz, D. \& Janssen, O. Antigen-induced death of T-lymphocytes. Front. Biosci. 2, d61-d77 (1997).

41. Peter, M. E. et al. Resistance of cultured peripheral T cells towards activationinduced cell death involves a lack of recruitment of FLICE (MACH/caspase 8) to the CD95 death-inducing signaling complex. Eur. J. Immunol. 27 1207-1212 (1997)

42. Larsen, S. E. et al. Sensitivity to restimulation-induced cell death is linked to glycolytic metabolism in human T cells. J. Immunol. 198, 147-155 (2017). 